\title{
Researches on Ominimedia Development Strategies and Core Competitive Strength Improvement in the Context of Triple Play
}

\author{
${ }^{1}$ Xu Zhiqiang, ${ }^{2} \mathrm{He}$ Jialiang, ${ }^{3}$ Liu Tong ${ }^{1}$ and Li Haidong \\ ${ }^{1}$ New Media Institute, Sichuan University of Media and Communications, China \\ ${ }^{2}$ College of Information and Communication Engineering, Dalian Nationalities \\ University, China \\ ${ }^{3}$ Department of Drama and Directing, Sichuan University of Media and \\ Communications, China \\ E-mail:1920281000@qq.com; \\ uchin2012@sina.com;695997819@qq.com;409247922@qq.com
}

\begin{abstract}
In the context of triple play Ominimedia is not just the simple combination of various media, but the aggregation of all media with different features, communication power and influences, and the interaction and mutual fusion among media of different forms and functions. This paper, based on the development trend of triple play, focused on the theme of Ominimedia, studied the traditional media development strategies to Ominimedia and analyzed in detail the strategies of cloud, tube, end and content aggregation. At the same time it explored the strategies for Ominimedia core competitive strength improvement from multiple dimensions of 3D media, communication channel, AirSharing and brand operation with the expectation of offering references to Ominimedia globalization in the context of triple play.
\end{abstract}

Keywords: triple play, Ominimedia, development strategy, core competitive strength, cloud, tube and end

\section{Introduction: Triple Play and Ominimedia}

Triple play refers to telecommunication network, broadcast network and Internet interacting and connecting with each other to achieve resource sharing. in the evolution process of broadband communication, digital TV network and next generation Internet, offering multiple services such as audio, data and broadcasting etc. ${ }^{[1]}$ whereas the core is Internet. Triple play does not mean three networks in one, but rather the fusion in service, that is, to perform different services such as voice, data and video etc. on the same network. Triple play triggered media end revolution, ends such as tablet PC ipad, smart phones, Internet TV (Google TV) gradually appear. On the same end, integrated media services and functions are born, eventually allowing media receivers to be in an Ominimedia environment. In 2010, our country refocused on triple play, and clearly specified the route chart, schedule, and 12 pilot cities. At the same time triple play was incorporated into national development strategy.

Ominimedia is to, under the premise of wide application and popularization of information, communication and transport protocols, interactively and comprehensively use multi-media approaches including text, figures, sounds, images, animation and video etc. to display the communicated content all day long, all round and three-dimensionally, at the same time to fuse different media forms (paper-based media, broadcasting, TV, Internet, mobile media)together, accordingly generating a new, open compatible and inclusive media communication form and operation mode, offering a receiving end integrating $\mathrm{TV}, \mathrm{PC}$ and Mobile phone through triple play, thereby acquiring the 
information required by users at anytime, anywhere using the most applicable means. In this way, receivers can gain timelier, accurate, precise, multi-dimensional media experience with greater satisfaction in audio and video. ${ }^{[2] " O m n i " ~ i n ~ O m i n i m e d i a ~ r e f e r s ~ t o ~}$ the completeness of products, media and ends. The key lies in achieving Ominimedia production, omni media communication and all-direction operation. ${ }^{[3]}$

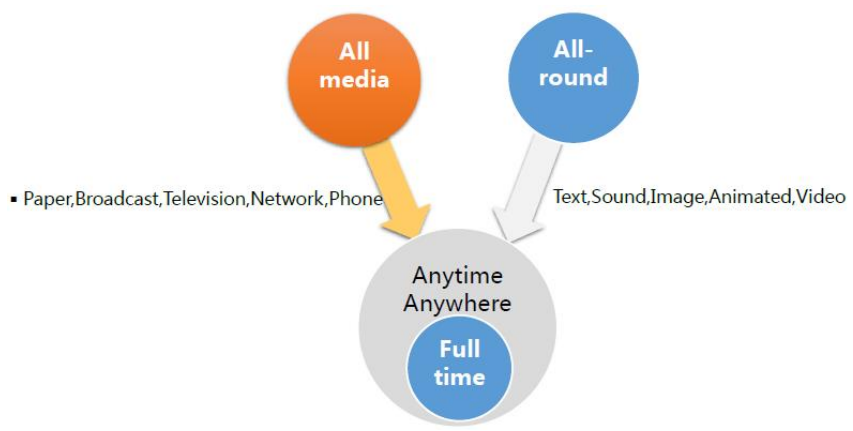

\section{Figure 1. All Media, Comprehensive, Full time of Expression Methods}

Some data indicate that in 2011 the output of smart phone reached 487.7 billion, exceeding that of PC (including tablet PC, laptop, note book and desktop) for the first time in the history. ${ }^{[4]}$ In 2013, the sales volume of smart phone exceed that of functional phone, ${ }^{[5] \mathrm{s}}$ the number of Internet users reached 270 billion, including 210 billion users of mobile Internet that is accounting for $75 \%$ of the total users. The number of global mobile Internet devices will reach 680 billion, almost equal to the total population of the earth. ${ }^{[6]} 3 \mathrm{G}$ accelerated the rising of Mobile Internet Industry, and $4 \mathrm{G}$ will be the accelerator of new-generation mobile Internet cross-industrial fusion and innovation.

In the context of triple play, this paper analyzed Ominimedia development strategies and discussed the strategies for Ominimedia competitiveness improvement in the hope of offering references to Ominimedia development and construction.

\section{Researches on Ominimedia Development in the Context of Triple Play}

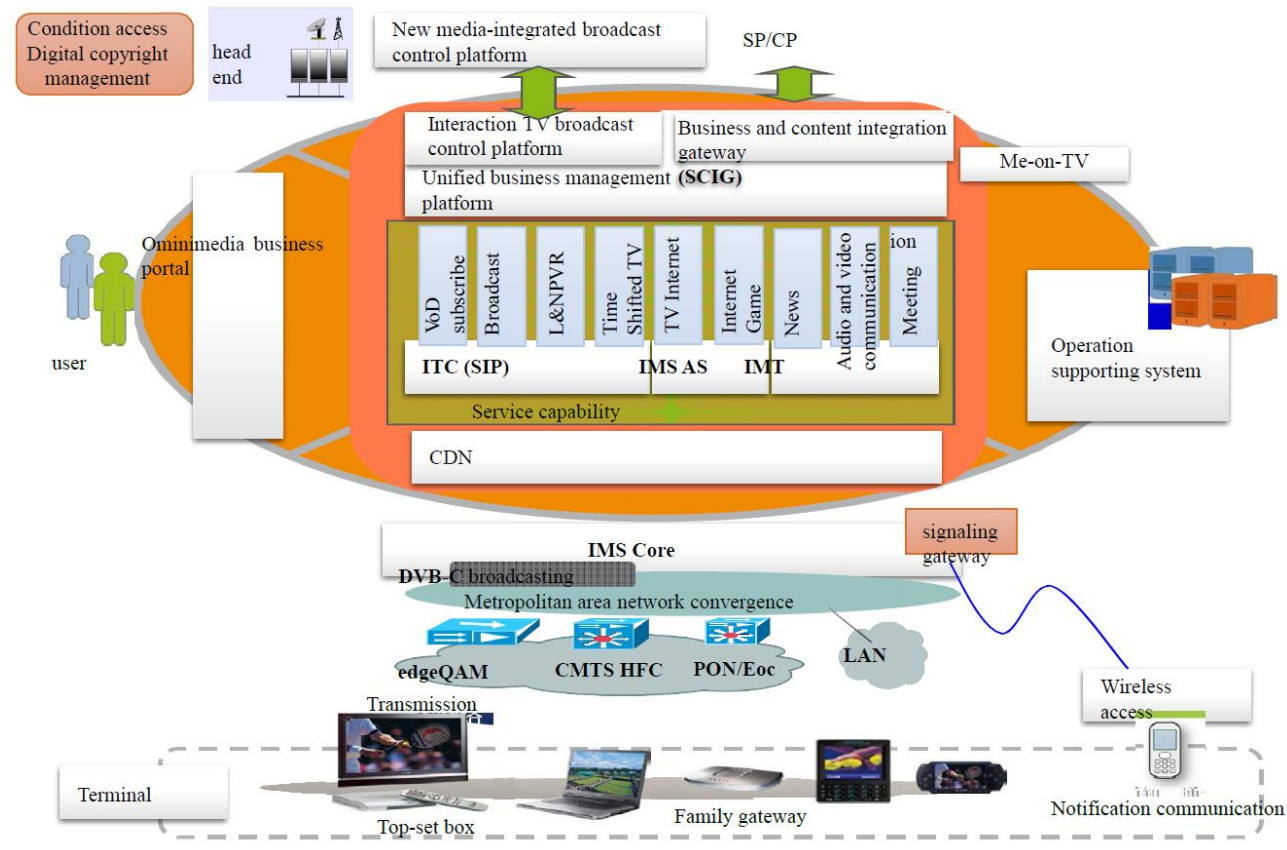

Figure 2. Ominimedia Business Platform Structure based on Triple Play 
The new trend of triple play has also proposed new missions and challenges to media cause development. In the general background of triple play, Ominimedia centered by innovative communication means began to explore positively to integrate media resources through omni media, space, time and service and to facilitate mutual fusion, promotion and common development. The communication platform featuring aggregated information will be Ominimedia with in-depth business fusion, accordingly triggering the market demand of "user-centered fusion service". In the context of triple play, Internet will play a more and more important role. Digital video-based new media has a promising future. Media convergence develops both vertically and horizontally, while various media form, ends and production are more and more professional and subdivided. The media end revolution triggered by Internet demands urgent changes in of traditional media business flow.

In the future era of information fragmentation and personalization, media will develop toward several directions: mobilization, communitization and cloud end. Through making use of the advantages of original content in traditional media, and the communication advantages of networking, digitalization and holographical in new media, fusion of products and technology gradually shifted to fusion of business and market, while multidirectional, multi-layer and multi-morphological contents gather together at the service platform and multi-channel releasing platform, developing into a communication and interaction platform offering timely and rich information to users relying a series of media expression approaches such as text, pictures, audio, community and social communication, eventually transforming the tradition media from content production to content communication and turning the challenges and pressures brought by new media into opportunities for traditional media.

\section{Ominimedia Development Strategies}

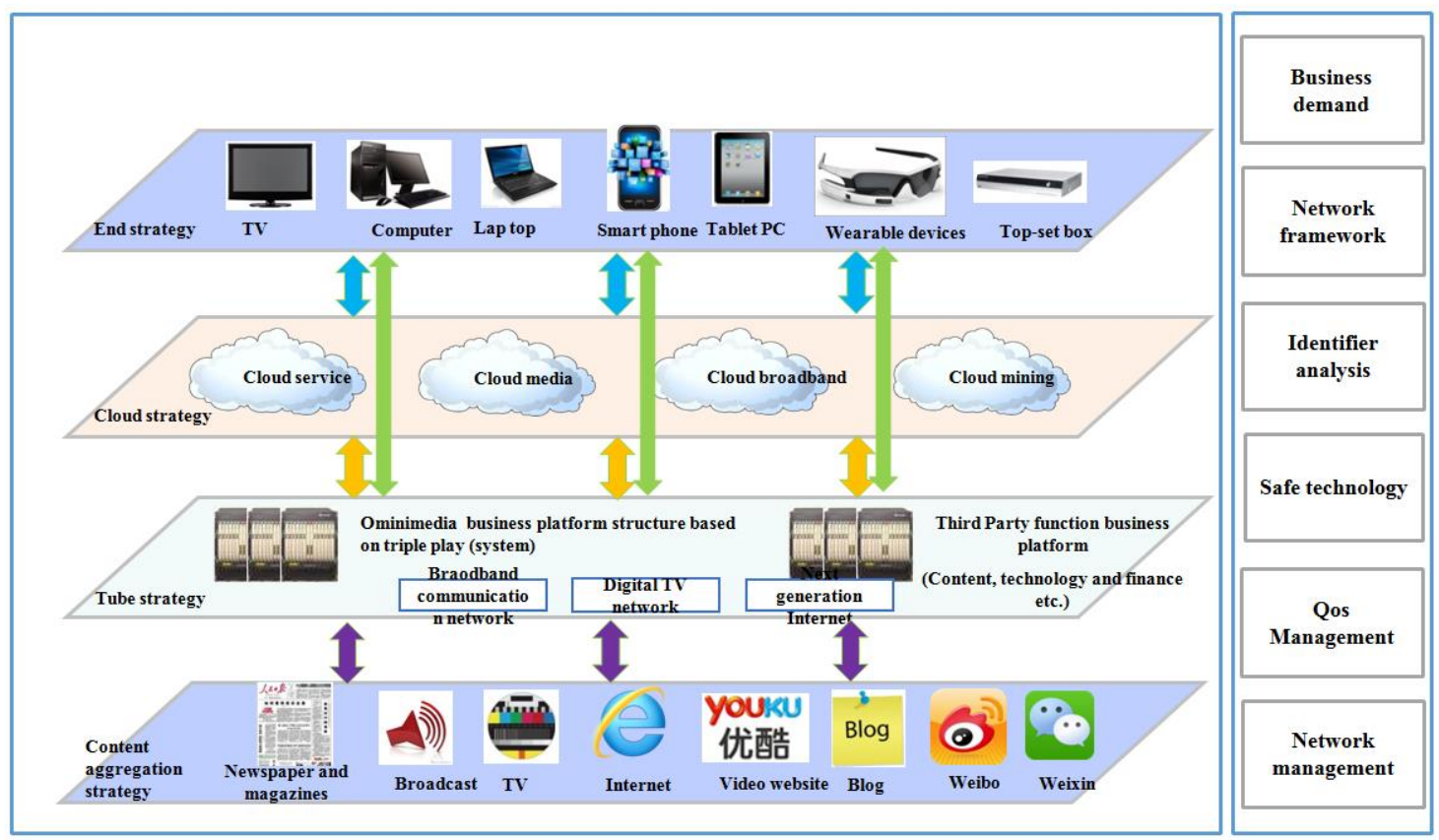

Figure 3. Ominimedia Strategic Framework based on Triple Play

The new information technology has accelerated the digitalization, networking and intelligentization of broadcasting video traditional media and will trigger new allocation mechanism of social resources. Therefore brand new collaborative 
technology and smart and high-efficient operation system are needed so as to cope with the ever-changing market. Both the internal and external media environments are changing significantly, which requires traditional media and new media develop together to enlarge receiver coverage using diversified and 3D products through pursuit of diversified media morphologies and communication channels with user and market as orientation, technology and commerce as drive force, network as foundation and OTT innovation as core, and open minds as guarantee. ${ }^{[7]}$ In tripartite confrontation situation of OTT, the organic combination of end, Internet and channel should be the best experience. Google has developed from cloud to tube and end, Apple from end to cloud and tube, and Softbank from tune to cloud and end. With the constantly developing and changing demands, Ominimedia development requires new strategies of "cloud-tube-end-content aggregation".

\subsection{Cloud Strategy}

Could, known as data aggregation, refer to the IT trend of business with the key issue of mass information processing. It will be the core of information service framework in the future. Cloud technology, with the general trend of its wide application, should rely on its resource superiority to innovate independently, timely, accurately and all-directionally enable cross-network, cross-screen, cross regional and multi-industrial intercommunication and interconnection, construct "cloud service platform, cloud media platform, cloud broadband platform and cloud mining platform", eventually facilitating the development of intelligent city and intelligent family.

Firstly, cloud service, taking various receiving ends as the best platform for users to communicate with the world and enjoy service, provides powerful storage and computation ability to users, and timely, fully and continuously offer users' diversified, personalized and informationalized demands. ${ }^{[8]}$ Secondly, cloud media can achieve rich content, diversified forms and conform content loading, actualize transboundary linkage and breaking point playing of TV end, PC end and mobile phone end, allow users to conveniently and safely enjoy mutual, interactive, high-resolution, 3D, personalized and high-end informationalized service anytime and anywhere. Thirdly, cloud broadband supports different online modes (wired or wireless), different ends of different operation system, and offers massive Internet data cache, images and nodes, accordingly enhancing the competitiveness of broadcasting and TV. Fourthly, cloud mining achieves separation of display and control. Large data analysis based on cloud end and context-awareness actualizes intelligent service and enhance users experience by enabling them to conveniently enjoy a healthy, comfortable, safe and energy-efficient living environment.

\subsection{Tube Strategy}

Tube, refer to the IP trend of Internet with the key problem of mass information transportation. It is also the foundation and premise for achieving new frameworks. Operators are required to build a new-generation network foundation framework using HSPA/LTE, FTTx, IP+optical fiber and NG-CDN.

Firstly, through construction of high bandwidth cadre network as support to fast and large-scale user development, reaching the goal of business flow optimization, service quality enhancement, investment cost reduction, service quality improvement and finding best business practice; secondly, in development of accessed Internet, attentions were paid to control of accessed tube instead of broadband; thirdly, through improvement of network intelligence, tubes which can be identified by users, differentiated in business, regulated in flow and managed in network" can be made for resource allocation as per user and business flexibility, finally enhancing operators' overall commercial values. 


\subsection{End Strategy}

End refers to APPs with the key of multimedia display of information. It will be widely applied to all industries. The integrated intelligent ends represent the development and revolution brought by Ominimedia-fusion between old and new media, disappearance of media boundary. In the future consumers may need a certain device for centralized management of all digital recreation equipments in daily life. Therefore, any media will be user-oriented end-centered. ${ }^{[9]}$ Users' desire, in return, forces channel and content to be adjusted as per end requirements. End-cauterization will be an important principle to be followed in Ominimedia era. ${ }^{[10]}$

This means first of all, control terminal extends from a single end to multiple ends, achieving fusion of network and business, and seamless connection of PC, TV and mobile phone; secondly actualize diversification of ends, develop capable, strong and intelligent ends as well as low-cost PC ends in order to offer high-speed, low-cost, smart and adaptive products based on using cloud system together. Thirdly build digital TV set-top box into "intelligent family end" and "the main urban informationalized platform", jointly using IT communication technologies such as RFID, WIFI, Zigbee, GPRS, twodimension code, media big data and teletransmission, construct new online and offline, physical and virtual operation modes of man-machine interaction, machine-machine communication, man-man connection, and thing-thing mutual inductance, offer convenient multi-media comprehensive services. Fourthly, relying on the existing user resources, develop a variety of mobile app products to enable mobile app to further fuse with people's life, study, entertainment and health, introduce socializing into traditional media programs to allow combination of products with services and to seize the dominance of mobile Internet in families, actualizing complete permeation of mobile phones.

\subsection{Content Aggregation Strategy}

Content aggregation, refer to recombination of content. Its key lies in information production and communication. Om is evolved from the concepts of multimedia, new media and cross-media. Its connotation and extension have all changed, and the measurement standard of its content changed too, while the variety and forms of news content are also more diversified. Being content-oriented has been another important principle to be followed in Ominimedia era.

With the rapid development of socializing media such as blog, video websites in China (particularly Weibo, Weixin, Yixin), the source of network information has changed from single and fixed channel to diversified and dispersive multiple centers. The information communicators are popularized to the public instead of professionals. In the past, consumers, as receivers, could be involved in content production conveniently. The fusion of content receivers and producers has subtly changed the content source and communication means. For traditional media, content aggregation production strategy plays an "axis" role in the development of Ominimedia. ${ }^{[11]}$ Content aggregation production strategy can be implemented by the following steps: integrate all resources such as undressed contributions, online contribution, externally captured data, finished data, historical data and clue data, embedded intelligent analytical data, organically fuse Ominimedia contents in interview, editing, storage, management and output, form digital film, content publishing and value-added business content aggregation and distribution, fuse news clues, editing and reviewing, tasks, planning and multiple releasing channel, finally form various featured Ominimedia products. ${ }^{[12]}$

The future competition is in fact the contest based on integrated platform of tripplebusiness fusion. Only by accelerating its own business extension and business mode evolution, can consumers acquire higher irreplaceable values than their competitors. Excellent enterprises should on one hand rely on their advantages, such as the end design 
of Apple, Internet service of Google, Softbank's foundation network, on the other hand filtrate into other two fields based on opposite theories of vertical and horizontal alliance of states with the state of Qin as pivot in order to get adapt to the mobile end, video content, and demassified communication. Then it is possible to achieve the general layout of "cloud-tube-content aggregation". A panorama-type, multi-dimensional and 3D report mode can be established. As the number of end user is growing, the generated data will be sent to cloud first, and cloud will analyze user demand based on data, achieving online translation of users' offline life, accordingly enriching the content of end. Demands are collected and interacted, rolled like snow ball and getting stronger and stronger.

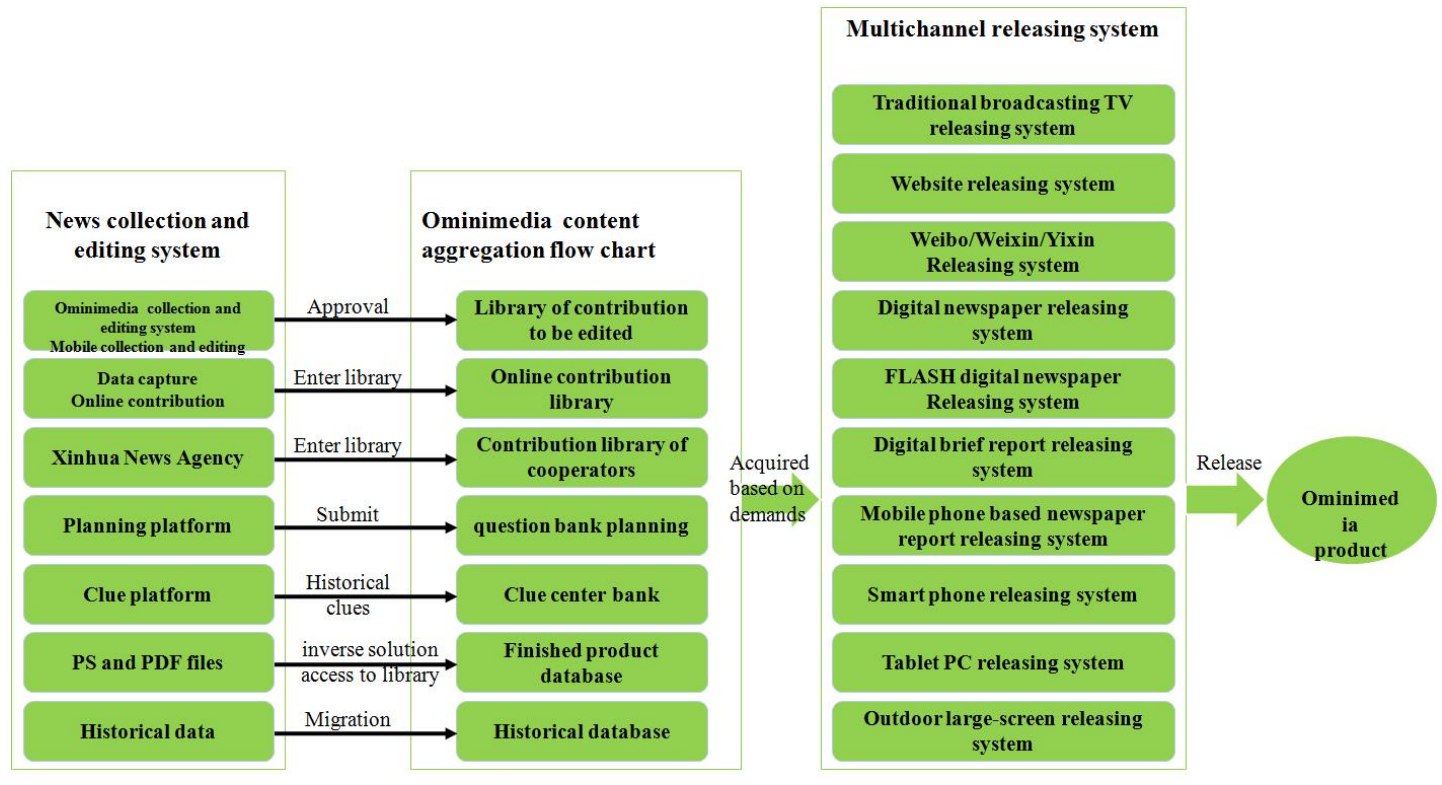

Figure 4. Ominimedia Content Aggregation Flow Chart

\section{Strategies for Improving Ominimedia Core Competitiveness}

Professor of Massachusetts Institute of Technology Ithiel de Sola Pool once pointed out that "divergence and convergence are two sides of the same phenomenon". With the advancement of ominimedia, in the future more attention may be paid to the "divergence" as the concomitant of "convergence". With the vigorous development of media cause and IT including mobile Internet, cloud computation and Internet of things, human beings gradually enters a Ominimedia era with the coexistence of traditional media such as newspaper, broadcasting, TV and new media including Internet, mobile phone media etc. All large-scaled news agency, broadcasting stations, network media should display their own advantages, make use of multimedia, multi-end and multi-platform systems, construct Ominimedia technological communication supporting system complying with the new media communication and high technologies, optimize communication business flow and product system,create core competitiveness and significantly promote newgeneration high-end intelligence and sustainable city construction. 


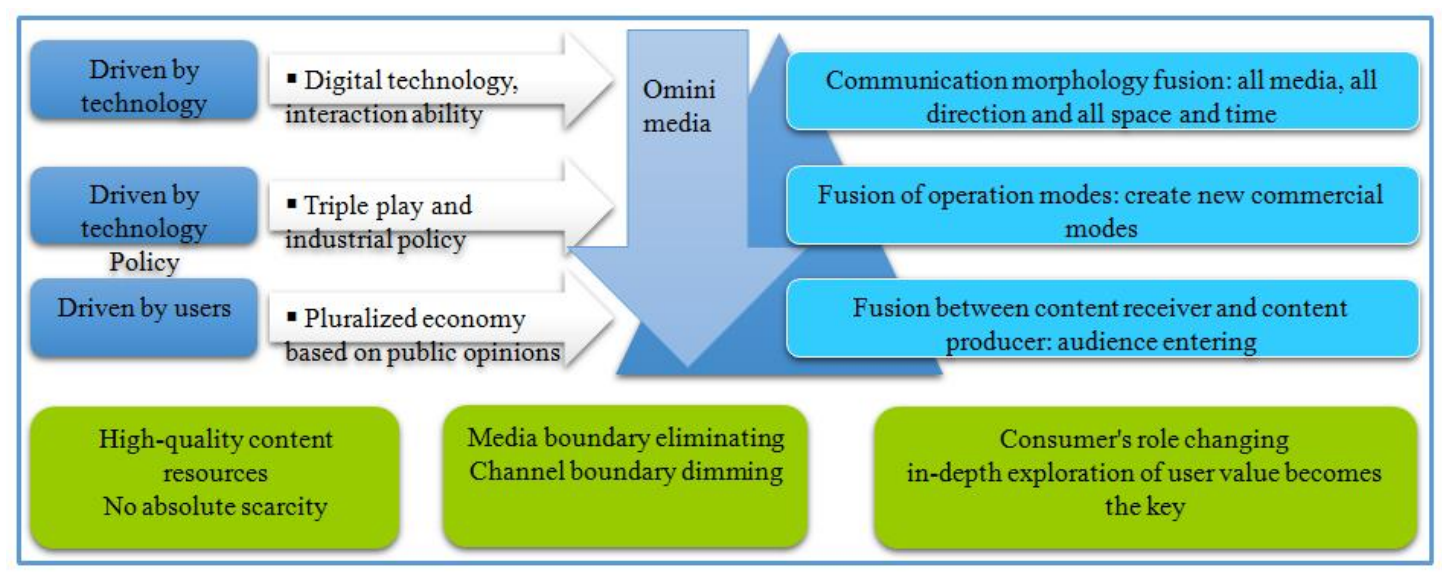

Figure 5. Strategies for Improving Ominimedia Core Competitiveness

\subsection{Shift from Traditional Print Media to Modern 3D Media}

Reform of information technology created new media and new value for media. Media convergence has been the main trend of global media development. Business handled by traditional media is based on independent flows and systems, accordingly resulting in difficulties in timely sharing and communication of information resources and inconvenience in data storage and transmission. All these are not easy for management. In new media era, Ominimedia news center should be established to achieve high integration of all media resources, including contribution resources, ads, clues, history, marketing resources and finished products etc. Famous media editors enter Ominimedia database and take the needed content to generate various end news products. The system supports remote/local editing and input of text, pictures, audios and videos, and transmits information to the center through special contributions and contributions to be edited. Contributions to be edited can be re-edited or revised by journalists. Special contributions are set with confidential period within which other media cannot view them. ${ }^{[13]}$ In addition to the specialized information gathering channels, media should also gradually expand socialized channel, reduce contents written themselves and increase contents from readers and receivers in order to display their functions of "aggregator and trustworthy navigator" to collect contents created by users. Therefore, application of integration thought in media utilization, promoting interaction and fusion of transitional and new media, and accelerating integrative development of newspaper, broadcast, TV, Internet and mobile phone can not only achieve the thought "one production, multi-channel release" which can enable traditional media resource to be utilized in a variety of new media, enhance the production and utilization efficiency of information resource, reduce the production cost of contents, but also meet receivers' personalized needs and preference, thereby achieving accurate and maximal communication effect, reaching a win-win situation of social and economic benefits and effectively improving the core competitiveness of media.

\subsection{Shift from Communication Content to Communication Channel}

Media industry and information industry has entered a new phase of in-depth fusion, and a new information blue sea is forming. New communication modes should feature new operation philosophies. Presently to shift from content-oriented" to channel-oriented to end-oriented has been an urgent task for the present media industry. Being end-oriented requires media to be a real " information provider" instead of traditional "content provider" to offer accurate, quality and latest information to users timely. ${ }^{[14]}$ The report cycle was more and more specified, from a daily based cycle for reporting yesterday's events to hour based cycle for reporting today's news and finally to every minute and 
second to report events happened just now. This requires smooth implementation of Ominimedia strategy, archive benign interaction between Ominimedia content production and value appreciation, well display the advantages of traditional media in in-depth and high-end text report and influential video program production, at the same time pay attention to new media users' thought and interactive user experience. A all-round consumer information feedback and scientific information searching and control platform can be built for creation of a compound and cross-type Ominimedia group, actualizing fusion of content, channels, technology and operation mode, inspire the vitality and creativity of market subjects, explore new commercial values and enhancing profitability.

\subsection{Shift from Single Screen to Multi-screen Iteration}

Multi-screen interaction refers to making use of multi-end of different operation systems (Android, iOS, Windows Phone,Windows XP/7/8 etc.) to offer bilateral and diversified contents to users and achieve interactive experience among different screens using intelligent terminal devices. With the deployment of high-speed wireless network, users' enhanced knowledge on intelligent terminals and the explosive growth of various APP, multi-screen enters an irresistible rapid development stage. For telecommunication operators, content resources are controlled by broadcasting and TV. They should make use of their abundant user resources to deeply process contents, and bring freshness feelings to users. For broadcasting and TV operators, Internet resources are controlled by telecommunication operators, so they should develop their own backbone network, transformed into a two-way ultra-wideband multimedia access network, the introduction of internet content, and increased content and user control means and digital rights management, introduction of radio and television content to television than other smart terminal, offer new services and multi-screen integrated user experience to create new profitable points.

\subsection{Shift from Media Operation to Brand Operation}

Presently with high degree of product homogenization, the best approach to build core competitiveness for media is to build their own image based on receivers, contents and product quality. Reinforcement of communication approaches and building core cultural brands are important measures for Ominimedia construction, as well as the main approach for traditional media to shift toward Ominimedia. Traditional media should also have specific brand construction and implementation plans, explore media resource sharing and interaction within a unified brand and content framework, make use of various social resources to serve users' systematicness and persistence, and crate values using multiple information and actualize brand shaping in all directions. Moreover, traditional media should also build complete media, special brand and new service relationship taking each program as unit module, gradually getting rid of its present unilateral profitable mode, form pluralized profitable modes based on interaction and common development of new media and industries, and finally create a few influential and powerful brand media clusters with open minds and innovative systems. ${ }^{[15]}$

\section{Conclusion}

Futurologist Nicholas Negroponte once said the key to understand future TV is not taking TV as TV but rather as a media that can be acquired randomly [16]. Media convergence in Ominimedia era is in fact complementing each media's advantages, realize functional fusion and mutual filtration, promote fusion and interaction among different media through news collection and communication flow reshaping so as to meet subdivided consumers' differentiated demands, enhancing 
the development speed, width and depth of Ominimedia. Om is advantageous for displaying a variety of media strength, integrate and allocation resources and optimize communication modes. Accelerating Ominimedia knowledge-based information and application integration service platform offers new possibilities to the transformation of media enterprises' communication values and facilitate the development of media economy. Implementation of Ominimedia strategies is an unavoidable path for traditional media.

Competition and cooperation, aggregation and integration are the key words in defining the development thoughts of old and new media in Ominimedia era, while crossnetwork, cross-application, cross-end and cross-media are the new industrial pattern developed by Ominimedia in the next step. As the triple play, media convergence, industrial convergence are boosted and deepening in our country, Ominimedia development will accelerate self-innovation, revolution, transformation in the deepened fusion process, and achieve new contributions as well.

\section{Acknowledgements}

This work was partially supported by A Project Supported by Scientific Research Fund of SiChuan Provincial Education Department "Development and Application Demonstration of Cloud Computation based Mobile New Media Comprehensive Teaching Service System"(Project No.14A0318), " Design and Actualization of Movie and TV Program Trade Platform Based on Big Data Technology”(Project No.14ZA0317).

\section{References}

[1] The State Council, "To promote the overall program triple play, the State Council [2010] No. 5", (2010).

[2] G. Wang, "Understanding and exploration of all media", China Radio \& TV Academic Journal, vol.11, (2012), pp. 8-11.

[3] C. Liu, "Shift in thinking and strategic implementation of the whole media era", Chinese Journalist, vol. 5, (2011), pp. 13-15.

[4] U.S. market research firm Canalys , "2011 Smart phone shipments for the first time over PC", Global smart phone and PC sales report, (2012).

[5] Gartner, "Annual sales of smartphones over feature phones first", Phoenix Technologies, (2013), http://tech.ifeng.com/telecom/detail_2014_02/14/33821770_0.shtml.

[6] International Telecommunication Union (ITU), "2013 Analysis of the Information Society", (2013).

[7] S. Cai and Y. Fan, "On the whole media strategy", Journalism \& Communication, vol. 6, (2011), pp. 912 ,

[8] Z. Xu and J. He, "Application Reality and Development Trend of Intelligent Terminal in the Context of Mobile Internet Era”, 2012 Internet Development Report in Beijing, People's Publishing House, (2013), pp. 152-167;

[9] W. Holman and Jr. Jenkins, "Sony strategy", The Wall Street Journal, (2004).

[10] S. Huang, "Triple play all media marketing", Journalism Review, vol.1, (2011), pp. 43-45.

[11] W. Cai, "All media strategy in the content production and innovation", News Front, vol. no. 1, (2013), pp.86-88.

[12] A. Huang and S. Cao, "BBC all media: the idea of change and strategic transformation", TV Research, vol. 12, (2013), pp. 38-40.

[13] G. Liu, "The development report of Chinese all media", Public Communication of Science \& Technology, vol. 2, (2010), pp. 81-87.

[14] Z. Xu and J. He, "Application Reality and Development Trend of Intelligent Terminal in the Context of Mobile Internet Era”, 2013 Internet Development Report in Beijing, People's Publishing House, (2013), pp. 78-91.

[15] F Gao and X. Sun, "Explore and practice of all media broadcasting under the triple play situation", China News Technology Association 2013 Annual Conference of Workers academic excellence award (2013).

[16] X. Liu and C. Zhang, “CNN's new media strategy”, TV Research, vol. 8, (2011), pp. 75-78. 


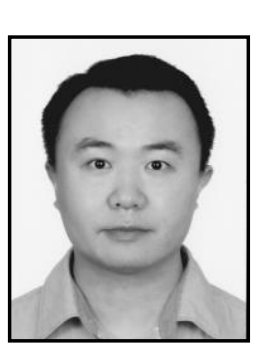

\section{Authors}

Xu Zhiqiang. Was born in September 1981. He achieved his Master of Science degree of Technopreneurship \& Innovation Program (TIP) in Nanyang Technological University in Singapore. $\mathrm{He}$ also is an assistant professor of Sichuan University of Media and Communications, China. He is a Senior Member of Institute of Electrical and Electronics Engineers (IEEE) and experienced on both theorical studies and practices on the fields of mobile internet, all media business, micro-video and media big data, the internet of things and cloud computing integrated media business etc. Until now, $\mathrm{Xu}$ has published over 20 journals, authorized (applied) more than 30 national patents, and owns more than 30 copyrights of software.

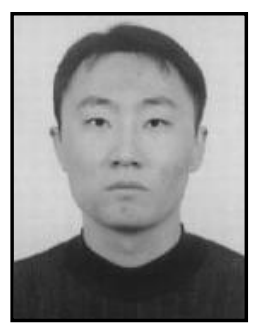

He Jialiang. Was born in 1977 , received the $\mathrm{PhD}$ degree in computer software and theory from Jilin University of China in 2012 and the Master degree in computer application from Jilin University of China in 2004. Now he is an associate professor at College of Information and Communication Engineering, Dalian Nationalities University, China. His papers have been published in some wellknown international Journals and IEEE conferences. His main interests include Mobile Internet, Internet of Things, and Intelligent Business Information Processing.

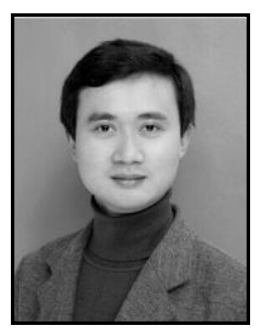

Liu Tong. Was born in 1984, deputy director, director and lecturer, Department of Department of Drama and Directing, Sichuan University of Media and Communications. "On the holiday TV Resources multidimensional development strategy" "China TV entertainment programs and landscape era" were awarded the SARFT 2009, 2011 "Starlight Award"; 2013 "tutorial" Introduction to radio and television review at the national level the Twelfth Five Year Plan textbook, "radio and television integration tutorial" review of Sichuan Province teaching plan; in 2013 to develop the" five self "applied art talents as the goal, won the two prize of teaching achievement of the seventh higher education in Sichuan Province Award to advance comprehensive reform of professional and practical" radio and television projects; 2013 monograph "lithography dream -- Micro story creation of" won the "prize three Sichuan Province Education Department the tenth philosophy social science research".

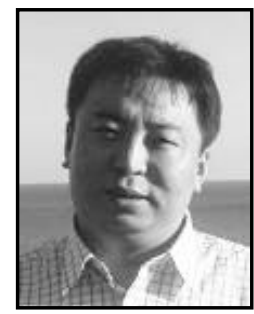

Li Haidong. Was born in 1970, Senior Systems Architect, Sichuan University of Media and Communications, China. Practices on the fields of mobile internet, all media business, micro-video and media big data, the internet of things and cloud computing integrated media business etc. Chair (primary research) provincial and ministerial research 2 . 